\title{
Application of a Mathematical Model of a Mineral Melting Cupola
}

Leth-Miller, Rasmus; Jensen, Anker; Glarborg, Peter; Jørgensen, Sten Bay; Jensen, L. M.; Jensen, L. M.

Published in:

Industrial \& Engineering Chemistry Research

Link to article, DOI:

10.1021/ie020450v

Publication date:

2003

Document Version

Peer reviewed version

Link back to DTU Orbit

Citation (APA):

Leth-Miller, R., Jensen, A., Glarborg, P., Jørgensen, S. B., Jensen, L. M., \& Jensen, L. M. (2003). Application of a Mathematical Model of a Mineral Melting Cupola. Industrial \& Engineering Chemistry Research, 42(26), 68936897. https://doi.org/10.1021/ie020450v

\section{General rights}

Copyright and moral rights for the publications made accessible in the public portal are retained by the authors and/or other copyright owners and it is a condition of accessing publications that users recognise and abide by the legal requirements associated with these rights.

- Users may download and print one copy of any publication from the public portal for the purpose of private study or research.

- You may not further distribute the material or use it for any profit-making activity or commercial gain

- You may freely distribute the URL identifying the publication in the public portal 


\title{
Application of a Mathematical Model of a Mineral Melting Cupola
}

\author{
R. Leth-Miller ${ }^{\dagger \ddagger}$, A.D. Jensen ${ }^{\ddagger}$, P. Glarborg ${ }^{\ddagger}$, S. B. Jørgensen ${ }^{\ddagger}$, \\ L.M. Jensen ${ }^{\dagger}$, P.B. Hansen ${ }^{\dagger}$ \\ ${ }^{\dagger}$ RockWool ${ }^{\circledR}$ International A/S, Denmark

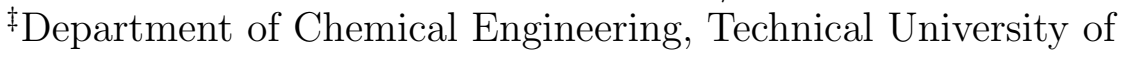 \\ Denmark \\ May 14, 2002
}

\begin{abstract}
A mathematical model of a mineral melting cupola furnace is used to illustrate how different process parameters affect the operation. The parameters studied include oxygen enrichment in the blast air, the influence of coke reactivity and coke size and the influence of raw materials melting point temperature and heat capacity.

The model is further compared to experimental data and rules of thumb for cupola operation at stone wool factories. The comparison with the rules of thumb indicates that the model has captured the essential phenomena in the process and describes gas concentrations, temperatures and flow rates inside the cupola well.
\end{abstract}

\section{Introduction}

The cupola furnace is the main technology used for melting raw materials (e.g. rocks and briquettes) in stone wool production and has been so for more than 70 years. In this period the cupola and its operation have been improved continuously. The improvements of cupola operation have mainly been achieved

*Corresponding author, e-mail: rasmus.leth.miller@rockwool.com 
through trial and error in ROCKWOOL ${ }^{\circledR}$ and also in the foundry industry development Viswanathan et al. (1997)). However, further development is becoming more and more difficult, since the most obvious improvements have already been made.

A mathematical model of a mineral melting cupola based on extensive experimental investigation on operating cupolas have been developed Leth-Miller et al. (2002a) to increase the knowledge about the cupola and facilitate new improvements in a systematic way. In this paper the model performance is compared to rules of thumb for cupola operation used in the stone wool industry. Furthermore the model is briefly described and simulations with the model are presented to illustrate its capabilities.

\section{Process Description}

A cupola furnace is a vertical shaft furnace, $4-6 \mathrm{~m}$ tall, with a diameter of $1-$ $2.5 \mathrm{~m}$ (cupolas in the foundry industry are often larger), see figure 1. Preheated air is blasted through a number of tuyeres (4 to 20) at the bottom of the furnace and coke and raw materials are fed from the top. The furnace is made of steel and is cooled with water in a cooling jacket to prohibit the steel from melting. In the cupola the downwards flow of coke and rocks are heated by the upwards flow of air and combustion products.

The coke burns in the bottom part of the furnace, and the combustion proceeds till the oxygen is consumed approximately $0.5 \mathrm{~m}$ above the tuyeres. In the zone $0.5-1 \mathrm{~m}$ above the tuyeres the hot gas from the combustion melts the rocks, and the upper part of the furnace acts as a simple preheater of the raw materials. Below the tuyeres is the melt bath, from where the melt is maintained at a certain level by a simple siphon.

The zone in the bottom where the oxygen is present is referred to as the combustion zone. Above the combustion zone is the reduction zone where $\mathrm{CO}$ is formed from gasification of the coke with $\mathrm{CO}_{2}$ and $\mathrm{H}_{2} \mathrm{O}$. The reduction zone extends upwards until the temperature has decreased sufficiently for the chemical reactions to virtually have stopped. The gasification is undesired since the reaction is endothermic and consume coke and the CO formed must be removed from the flue gas, typically by the use of an afterburner. The zone where the raw materials melt is referred to as the melting zone. The melting zone overlaps the combustion zone or the reduction zone or both.

The melt temperature (i.e. the temperature of the melt leaving the cupola) is a key parameter in the production since it determines the viscosity of the melt when it reaches the spinning machines, and thereby influences the quality of the 


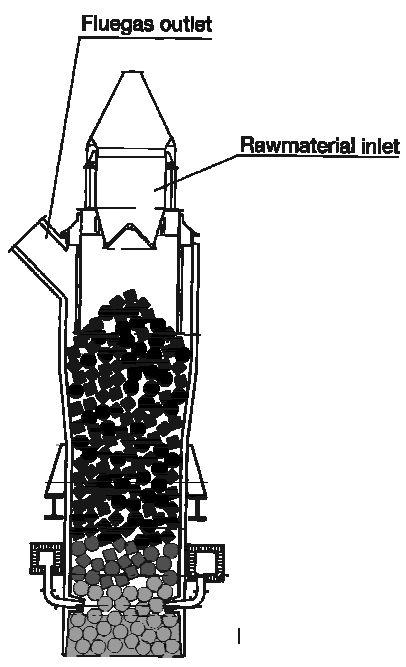

Figure 1. Cupola furnace.

wool. The cupola operation is mainly controlled to adjust the melt temperature and the capacity. The control actuaters are mainly the coke percentage (i.e. the mass fraction of coke in the charge) and the blast air flow rate.

\section{Model}

The model of the mineral melting cupola furnace is a steady state 1-D mathematical model, see Leth-Miller et al. (2002a) for details. The spatial dimension is the vertical position. The model consists of mass and energy balances for the gas species, four different types of raw materials and coke. It accounts for mass and heat transfer between coke, gas and four raw material phases and heat loss to the water cooled wall. The model includes seven chemical reactions: combustion of the coke, $\mathrm{CO}$ and $\mathrm{H}_{2}$, gasification of the coke with $\mathrm{CO}_{2}$ and $\mathrm{H}_{2} \mathrm{O}$, calcination of lime and reduction of iron oxides. It accounts for mass and energy balances of the gas phase, coke and four different raw material phases. Mass transfer between the gas and the coke is modelled using a mass transfer coefficient to particles in a fixed bed. Heat transfer includes both convection and radiation.

The model is discretised using orthogonal collocation Villadsen and Michelsen (1978) and the system of equations is solved with the Levenberg-Marquardt method Dennis and Schnabel (1983) and Newton-Raphson, Rice and Do (1995). 
The model predicts the output of the cupola for a given input, i.e. the coke percentage, coke type, raw material types, charge composition and blast air temperature, flow rate and composition is specified and then the model predicts melt capacity, flue gas composition and temperature, melt temperature, and mass flows, temperatures and gas concentrations inside the cupola.

\section{Comparison with Rules of Thumb}

During the more than 70 years that the cupola has been used in RocKwooL ${ }^{\circledR}$ a number of rules of thumb for the operation has developed. In this section the cupola model is compared to some of these rules as a test of the model and to further investigate whether the model has captured the essential phenomena in the process.

One of the rules of thumb used is that adding $1 \%$ coke to the charge will increases the melt temperature with $20 \pm 20^{\circ} \mathrm{C}$. The rule is not very precise because different cupolas have been observed to behave very differently and the rules of thumb are averages of all these observations. Table 1 shows the results of some simulations. It can be shown that the melt temperature decreases $16^{\circ} \mathrm{C}$ when the coke percentage is decreased from $13 \%$ to $12 \%$, and that the melt temperature increases $15^{\circ} \mathrm{C}$ when the coke percentage increased from $13 \%$ to $14 \%$. The results of the model is in good agreement with the rule of thumb.

Another rule of thumb is that if the blast air temperature is increased $100^{\circ} \mathrm{C}$ it is possible to save $0.7 \%$ coke and sustain the same melt temperature. In table 2 results of three simulations are shown in terms of coke percentage as function of blast air temperature. The table shows that the model predicts that $1 \%$ of coke can be saved for each $100^{\circ} \mathrm{C}$ the blast air temperature is increased. This is also in good agreement with the rule of thumb.

Table 1. Simulation results compared to the rules of thumb (RoT) that are used in RockWool ${ }^{\circledR}$. RoT say that increase of $1 \%$ coke increases the melt temperature with $20 \pm 20^{\circ} \mathrm{C}$.

\begin{tabular}{ccc} 
Coke & \multicolumn{2}{c}{ Melt temperature } \\
percentage & RoT & Model \\
\hline 12 & 1465 & 1469 \\
13 & 1485 & 1485 \\
14 & 1505 & 1500 \\
\hline
\end{tabular}


Table 2. Simulation results compared to the rules of thumb (RoT) that are used in Rockwool ${ }^{\circledR}$. RoT says that an increase of $100^{\circ} \mathrm{C}$ of the blast air temperature saves $0.7 \%$ coke.

\begin{tabular}{lcc}
$T_{\text {Blast air }}$ & \multicolumn{2}{c}{ Coke percentage } \\
& RoT & Model \\
\hline 600 & 11.5 & 11.5 \\
700 & 10.8 & 10.5 \\
800 & 10.1 & 9.5 \\
\hline
\end{tabular}

Table 3. Simulation results compared to the rules of thumb (RoT) that are used in RockwooL ${ }^{\circledR}$. RoT says that a decrease from full capacity to $70 \%$ capacity costs $1 \%$ extra coke.

\begin{tabular}{lcc}
$V_{\text {Blast air }}$ & \multicolumn{2}{c}{ Coke percentage } \\
& RoT & Model \\
\hline Max. & 13.0 & 13.0 \\
$70 \%$ of max. & 14.0 & 13.9 \\
\hline
\end{tabular}

The last rule of thumb says that a decrease in blast air amount from the upper capacity limit to $70 \%$ of the capacity limit costs $1 \%$ of coke to sustain the same melt temperature. Table 3 shows results of two simulations in terms of coke percentage. The simulations show that $0.9 \%$ extra coke is needed when the production of the cupola is decreased from maximum capacity to $70 \%$ of the full capacity and still sustain the same melt temperature. Again good agreement is obtained.

The comparison of the model to the three rules of thumb shows good agreement indicating that the model reliably predicts the static behaviour of an operating cupola furnace.

\section{Parametric Study}

In this section examples of the model capabilities are given. There is some empirical knowledge about how changes in operating conditions affect the outputs of the cupola. However the knowledge is in general limited to the direction that the output changes when one parameter is changed. With the present knowledge it is difficult to say much about the effect of changes of several parameters simultaneously. An overview of this can be obtained with the model as illustrated with the following examples. 


\section{Oxygen Enrichment}

On some production lines the blast air is enriched with oxygen. There has been discussion in the stone wool industry whether this improves the energy efficiency of the cupola or not. There is no doubt that oxygen enrichment can increase the capacity of a cupola, since the limiting factor is the amount of blast air. If oxygen is added to the blast air more coke can be burned and thus the capacity is increased. With respect to the efficiency improvement it has been observed that coke can be saved on some lines while the impact on other lines has been very modest when the blast air is enriched with oxygen.

The cupola model has been used to simulate different scenarios to investigate what coke percentage was needed to sustain a certain melt temperature as function of oxygen content in the blast air.

Figure 2 shows the required coke percentage to maintain a certain melt temperature as function of the oxygen content in the blast air. Simulations have been made for two different blast air temperatures of $500^{\circ} \mathrm{C}$ and $800^{\circ} \mathrm{C}$. The plots show that at low oxygen content $\left(18 \%\right.$ for $500^{\circ} \mathrm{C}$ and $15 \%$ for $\left.800^{\circ} \mathrm{C}\right)$ the curve is steep, which means that relative more coke can be saved when the blast air is enriched with oxygen. The possible efficiency improvement of oxygen enrichment depends on other operation conditions.

The results have been more closely examined to explain to the observations. Increase of the blast air temperature and increase in oxygen content in the blast air have similar effects on the temperature profiles as illustrated in figure 3. When either of the two parameters is increased the temperature in the combustion zone becomes higher and the peak more narrow. The more narrow temperature peak decreases both the $\mathrm{CO}$ formation and the cooling water loss, and the higher temperature ensures that the melt is still heated to the desired temperature. Since the influence on the temperature profiles is similar for the two changes in operation conditions the combined effect of both changes at the same time can not be obtained.

Whether or not the blast air should be enriched is a question of whether the money that can be saved by reducing coke is sufficient to pay for the oxygen enrichment. This depends on the location of the factory, i.e. the local coke, oxygen and transportation costs. 


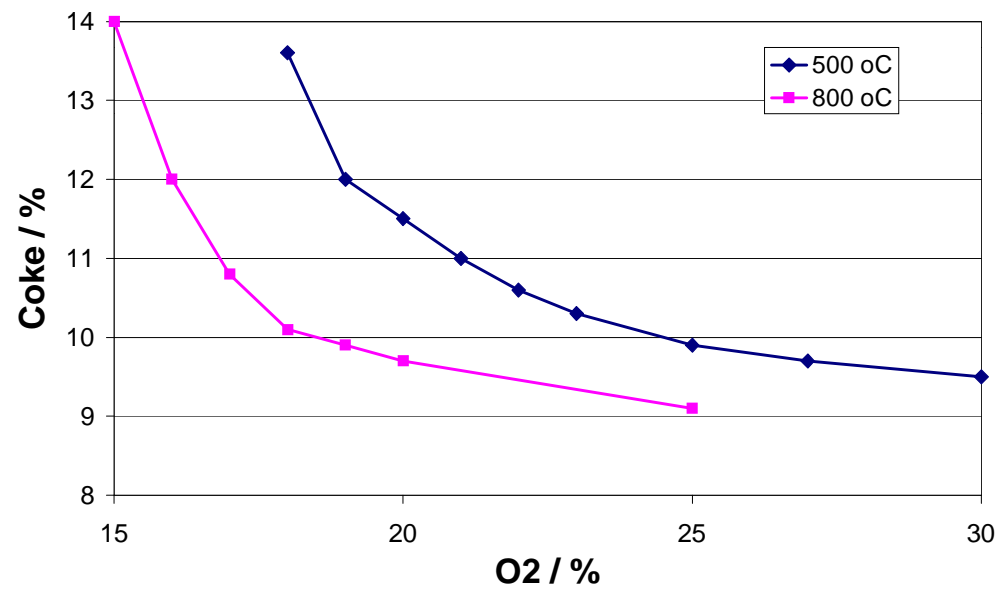

Figure 2. Coke consumption as function of oxygen concentration in the blast air predicted by the cupola model.

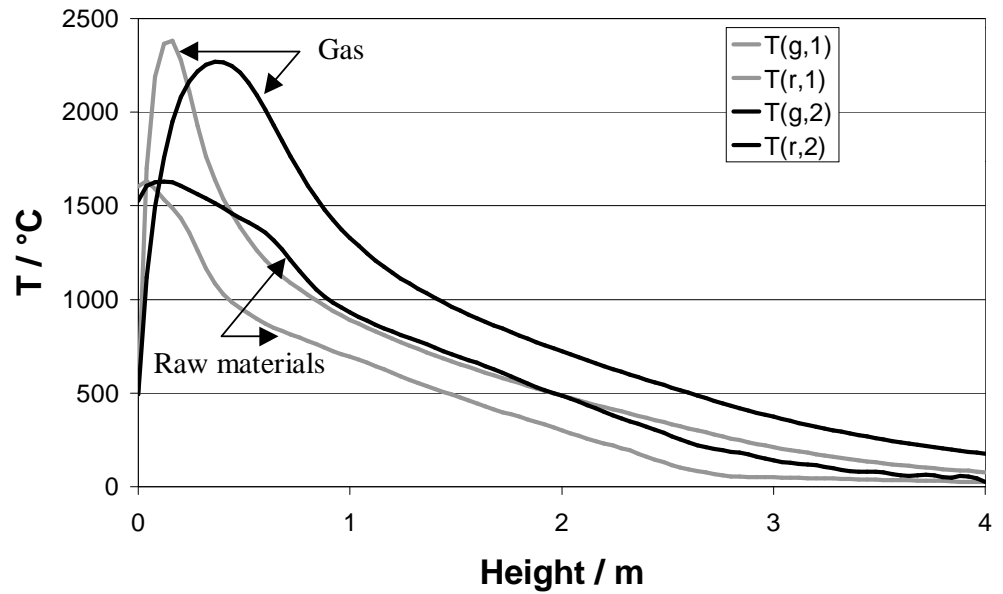

Figure 3. Temperature profiles of gas $(g)$ and raw material/melt $(r)$ from two simulations. $H=0$ is at tuyere level, and $H=4 \mathrm{~m}$ is the top of the cupola. The base situation is marked with 2 while the profiles marked 1 illustrated either oxygen enrichment or higher blast air temperature. 


\section{Coke Size}

Traditionally foundry coke (large coke, $\varnothing \approx 200 \mathrm{~mm}$ Hafner $(1984)$ ) has been used also in mineral melting cupolas. Recent development on the coke market has made it interesting to consider metallurgical coke (small coke, $\varnothing \approx 50 \mathrm{~mm}$ Hafner (1984)) because the foundry coke from China has been taxed in EU leading to a general price increase of foundry coke in Europe. In this section the dependence of the coke size is investigated through simulations with the cupola model.

Figure 4 shows results of a number of simulations. The coke consumption to sustain a given melt temperature is plotted against the coke size for two blast air temperatures. The plot shows that for both blast air temperatures less coke is needed as the coke size increases. However, the sensitivity is largest for the low blast air temperature $\left(500^{\circ} \mathrm{C}\right)$. The case with the high blast air temperature $\left(800^{\circ} \mathrm{C}\right)$ is less sensitive because the temperature is lower in the most of the cupola, as illustrated in figure 3 , and the CO formation is thus lower. The reason that more $\mathrm{CO}$ is formed in the cupola and thus more coke is consumed by gasification reactions and energy is lost when using smaller coke is that they have a larger surface area per mass.

The relative price difference on the large and small coke is the main influence on the decision of which coke to use. However, the simulations show that cupolas running on $800^{\circ} \mathrm{C}$ blast air are more likely to benefit from smaller coke than cupolas running on $500^{\circ} \mathrm{C}$ blast air.

\section{Coke Reactivity}

Several types of coke are used for stone wool production. The coke types differ by reactivity as well as other characteristics of the coke Leth-Miller et al. (2002c). The coke reactivity is expected to influence the cupola operation in several ways. The reactivity towards oxygen can have an influence on the combustion and the reactivity towards $\mathrm{CO}_{2}$ can have an influence on both the combustion and the $\mathrm{CO}$ formation in the reduction zone. The reactivity towards $\mathrm{CO}_{2}$ affects the combustion because the $\mathrm{CO}_{2}$ also reacts with the coke in presence of oxygen, but the $\mathrm{CO}$ formed is immediately combusted in the gas phase as long as oxygen is present. $\mathrm{CO}_{2}$ acts in this way as a carrier of carbon from the coke to the gas phase in the combustion zone. The general perception in the stone wool industry has been that low reactivity coke was desired to minimise CO formation thereby energy loss.

The impact of different coke reactivities were investigated with the cupola 


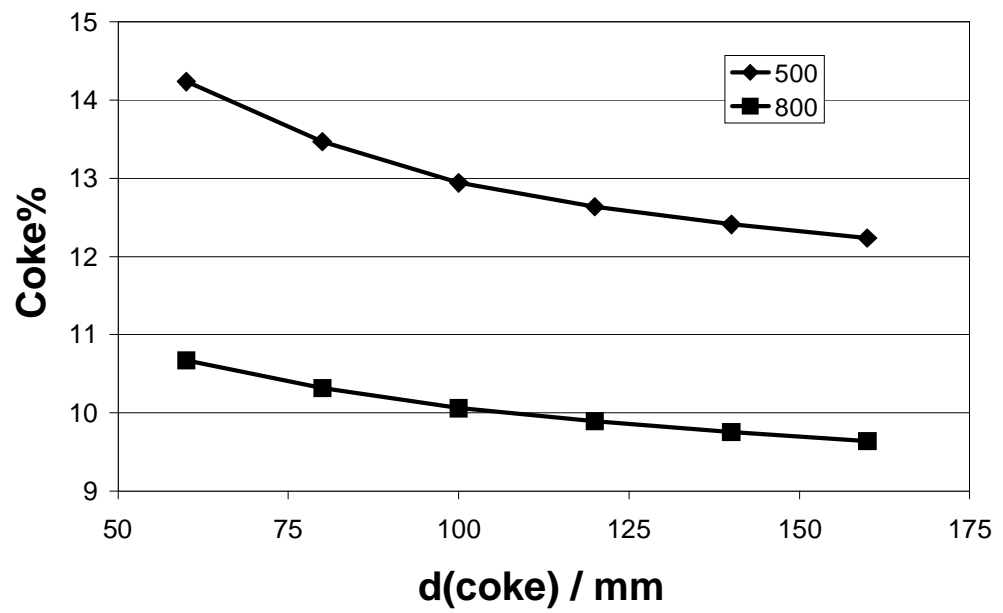

Figure 4. Coke consumption as function of coke size predicted by the model. The coke consumption is adjusted to sustain a given melt temperature.

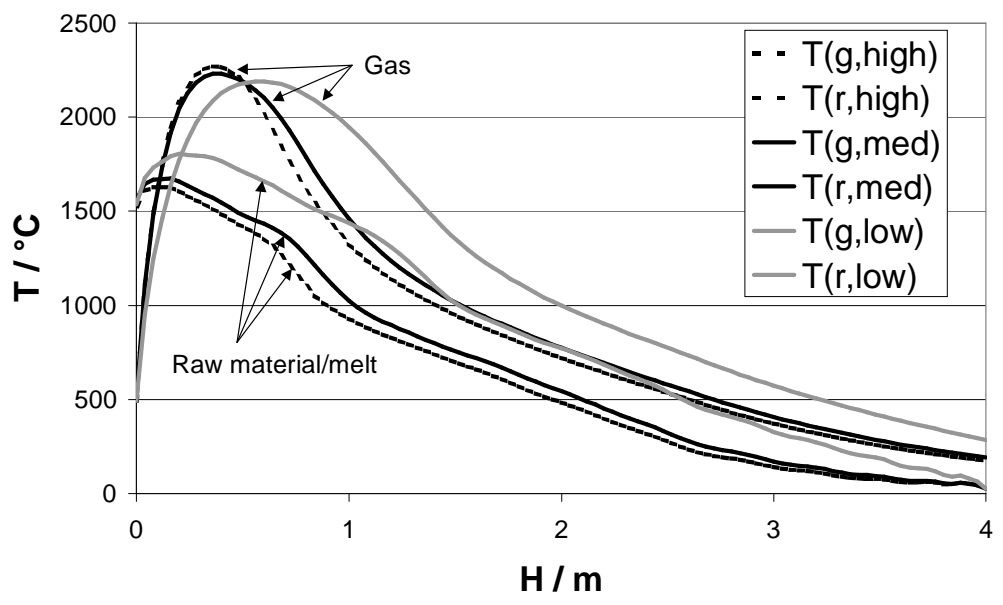

Figure 5. Gas and raw material temperature profiles from three different simulations with varying coke types. Profiles marked with high is the standard coke. The med coke has half the reactivity towards $\mathrm{CO}_{2}$ of the standard coke. The low coke has half the reactivity towards $\mathrm{O}_{2}$ and $\mathrm{CO}_{2}$ of the standard coke 
model. Figure 5 shows temperature profiles from three simulations. Three simulations have been made with cokes of varying reactivity. The most reactive coke is marked high. The medium reactive coke, marked med, has half the reactivity towards $\mathrm{CO}_{2}$ as the most reactive coke. The least reactive coke has half the reactivity towards both $\mathrm{O}_{2}$ and $\mathrm{CO}_{2}$ than the most reactive coke. In the case of the least reactive coke the coke percentage was increased from $13.5 \%$ to $17 \%$ to maintain the same melt temperature.

Figure 5 shows that the temperature profiles of the high and medium reactive cokes are very similar. The most reactive coke has a little higher peak temperature and a slightly more narrow peak than the medium reactive coke. The temperature of the melt leaving the cupola (i.e. at $H=0$ ) in the case of the medium reactive coke is slightly higher. The simulation indicates that coke with lower reactivity towards $\mathrm{CO}_{2}$ forms less $\mathrm{CO}$ in the reduction zone and therefore releases more heat in the combustion zone resulting in a higher melt temperature, thus providing a higher thermal efficiency of the cupola.

Figure 5 shows that the temperature profiles of the least reactive coke is different from the other cokes. The least reactive coke has a much broader peak and a lower peak temperature located further up in the cupola than in the other two cases. More coke is needed because of the lower peak temperature and the position and width of the peak.

The choice of coke depends on several other parameters apart from reactivity, such as ash content, heating value, size (as illustrated above), mechanical strength and of course price. These simulations can help make the choice on a rational basis in terms of furnace performance.

\section{Raw Material Properties}

Several different raw materials are used in stone wool production. In this section the influence of changes in melting point temperature and changes in heat requirements on the coke percentage is investigated. The coke percentage is determined to maintain a certain melt temperature.

Four simulations have been made with raw materials with different heat capacities. The heat capacities are related so that $c_{p, i}=(1+0.1 \cdot i) c_{p, 0}$ where $i$ denotes the number of the raw material and raw material 0 is the base. The enthalpy is

evaluated as $H_{1500}=\int_{298 \mathrm{~K}}^{1773 \mathrm{~K}} c_{p} d T$. For each raw material the coke percentage for maintaining a certain melt temperature is found. The enthalpy range selected for the simulations cover the range that has been found in measurements of raw material enthalpies and the heat of fusion was set to zero Leth-Miller 
et al. (2002b). The results are plotted in figure 6 . The figure shows that the coke percentage and enthalpy are almost linearly proportional.

Simulations of cupola operation with raw materials with different melting points have been made. The coke percentage needed to maintain a certain melt temperature is found. Figure 7 shows the coke percentage plotted against the melting point of the raw materials. The melting point temperature range covers the range found in measurements by Leth-Miller et al. (2002b). The figure shows that there is a minimum on the curve. Below the minimum the slope is very steep indicating that even a little decrease of the melting point temperature below the minimum is expensive, while the influence above is not as pronounced. The reason that more coke is needed when the melting point temperature is lowered is that the residence time of the raw material is short after it has melted and hence the temperature must be higher in the combustion zone to assure that the melt formed at low temperature is heated sufficiently. Higher melting

point temperature of the raw materials require more coke because raw materials will be present in the combustion zone resulting in smaller coke surface area in the combustion zone and thus lowering the temperature in the combustion zone.

\section{Hydrogen Enrichment}

In this section simulations with hydrogen enrichment of the blast air are described. The hydrogen enrichment is made to simulate fuel supplied through the tuyeres. Figure 8 shows the coke percentage necessary to maintain a certain melt temperature. The coke percentage decreases from $13 \%$ at $0 \% \mathrm{H}_{2}$ in the blast air to $9.1 \%$ at $12 \%$ hydrogen in the blast air. The slope is steeper at low hydrogen concentrations than at high concentrations. Hydrogen enrichment has a similar impact on the temperature profiles as oxygen enrichment. The temperature peak becomes more narrow and the peak temperature higher. The hydrogen enrichment also shifts the peak downwards because the combustion of the hydrogen occurs very close to the tuyeres and only $100 \mathrm{~mm}$ above the tuyeres the hydrogen concentration has dropped to zero.

Figure 9 shows the energy distribution between coke and hydrogen per mass produced melt plotted against the hydrogen concentration along with a summation of the two. The summation in figure 9 has a minimum at a hydrogen concentration of $10 \%$. The minimum indicate the operation point where the cupola is most energy efficient. This is, however, not necessarily the operating point where the production is most profitable, because this depends on the fuel (coke, natural gas, etc.) prices.

Hydrogen is too expensive to be a realistic fuel, but it is used in the simulations 


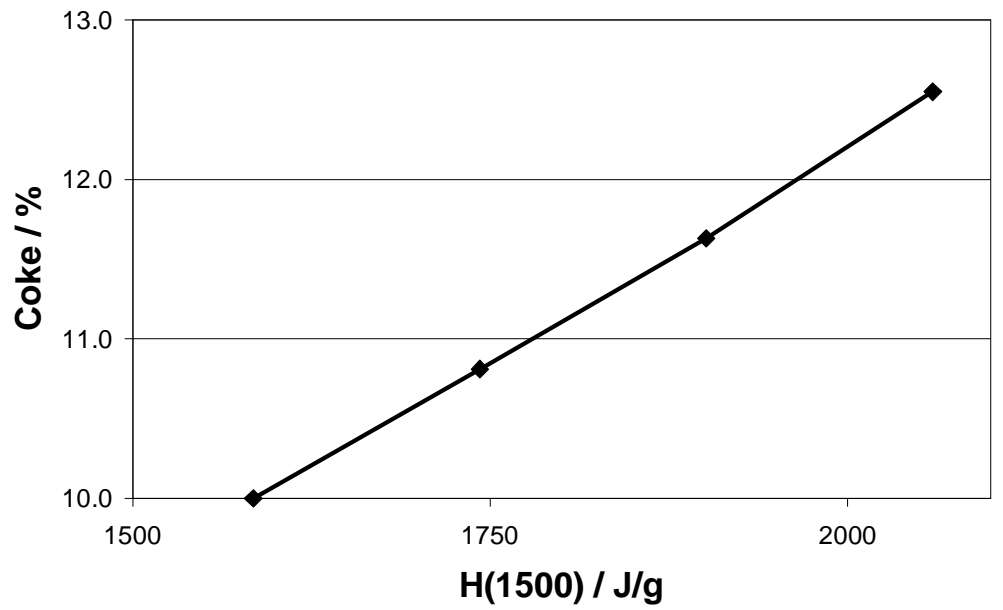

Figure 6. Coke percentage plotted against raw materials enthalpy, $H_{1500}$. The coke percentage is determined to maintain a certain melt temperature. $H_{1500}$ is the heat needed to heat, melt and superheat the raw material from $25^{\circ} \mathrm{C}$ to $1500^{\circ} \mathrm{C}$.

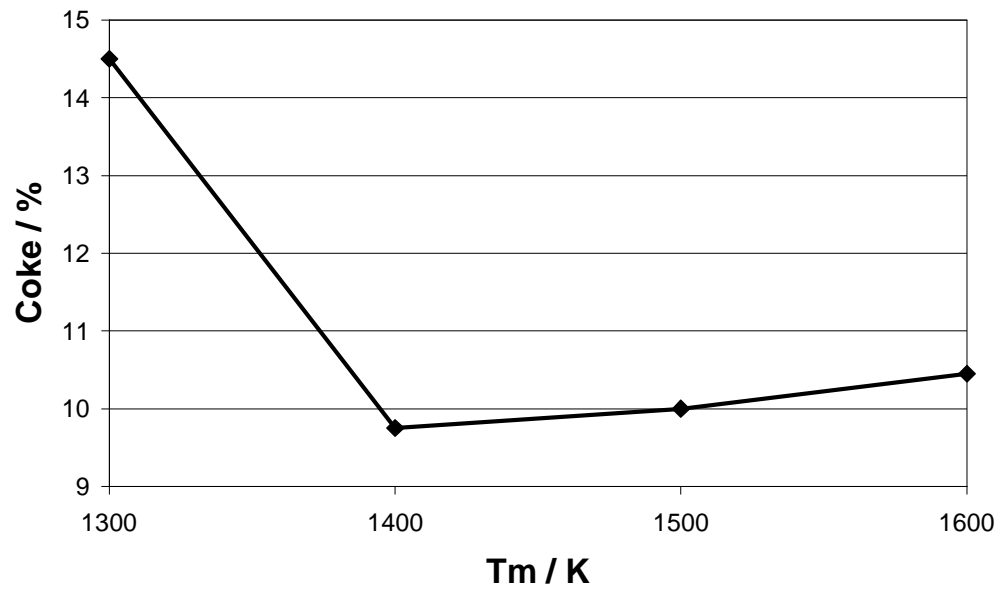

Figure 7. Coke percentage plotted against the melting point temperature of the raw material. The coke percentage is determined to maintain a certain melt temperature. 


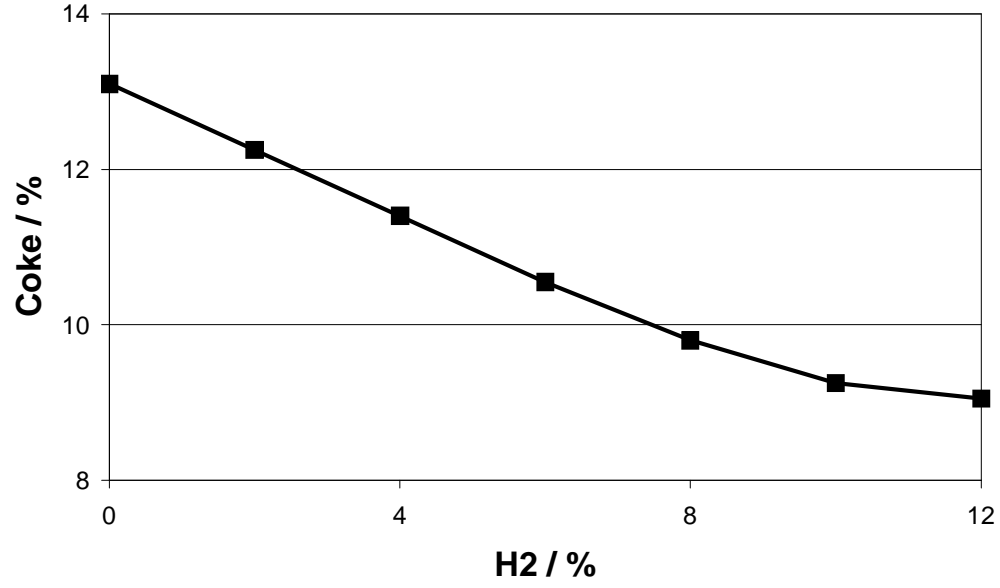

Figure 8. Coke percentage necessary to maintain a certain melt temperature as function of hydrogen concentration in the blast air.

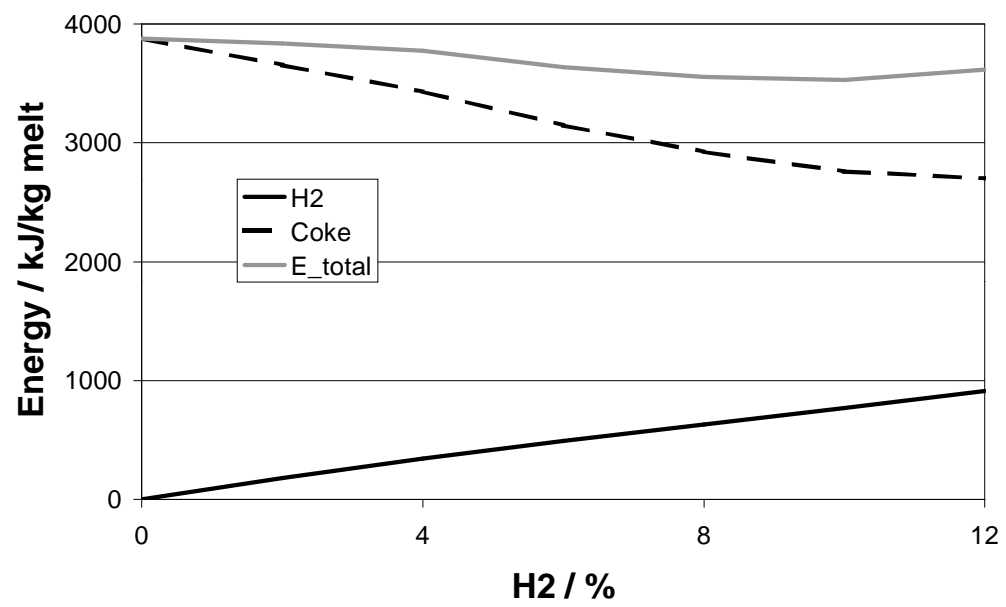

Figure 9. Energy supplied to the cupola per mass of melt produced plotted against hydrogen concentration in the blast air. Curves of energy in the hydrogen and in the coke supplied and a summation of the two are included. 
because the model does not handle more realistic fuels such as coal or natural gas. The choice of fuel affects the gasification reactions since it changes the ratio of $\mathrm{H}_{2} \mathrm{O}$ and $\mathrm{CO}_{2}$ in the gas leaving the combustion zone.

\section{Raw Material Diameter}

In this section the influence of the raw material diameter on cupola operation is investigated. Figure 10 shows the coke percentage needed to maintain a certain melt temperature plotted against the raw material size. The necessary coke percentage increases as the raw material diameter increases. The sensitivity of the coke percentage towards the raw material diameter is largest at small diameters (the slope is steeper). The results reflect that smaller raw materials have a larger surface area and are therefore more easily heated. Changes in raw material size has little effect on width of the peak on the temperature profile and the peak temperature. The difference is that the flue gas temperature is higher when large raw materials are used, i.e. more energy is lost in the flue gas.

Interpretation of the simulations using different raw material sizes should be made with caution since the raw material diameter may affect the bulk porosity of the cupola, which influences the counter pressure in the cupola. This is not included in the model which assumes a constant porosity. Small raw materials will plug the cupola and reduce the maximum production rate which requires extra coke (see table 3 ).

\section{Conclusion}

A model of a mineral melting cupola furnace used for stone wool production developed by Leth-Miller et al. (2002a) has been compared to rules of thumb for cupola operation to test the qualitative capabilities of the model. Applications of the model have been illustrated with studies of influence of oxygen enrichment in the blast air, of the influence of coke reactivity and coke size and of the influence of raw materials melting point temperature and heat capacity.

The rules of thumb have evolved over the years in RockwooL ${ }^{\circledR}$ and include the coke percentage on melt temperature, blast air temperature on necessary coke percentage and blast air flow on necessary coke percentage. In general the model predicts similar changes as the rules of thumb.

The simulations with the model further showed that the influence of a change 


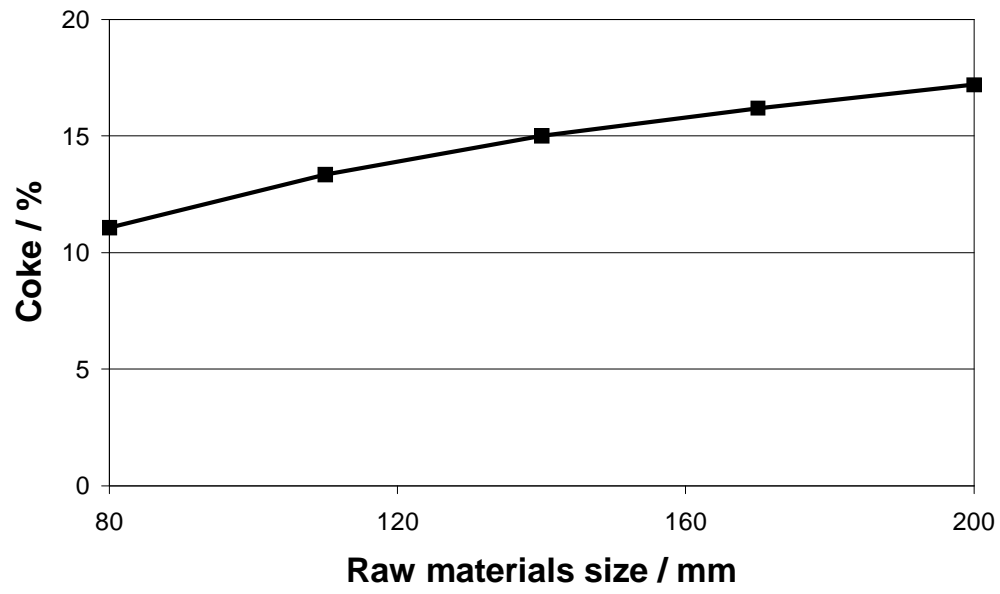

Figure 10. Coke percentage needed to maintain a certain melt temperature plotted against raw material diameter.

in an input dependence on the initial conditions. For example more coke can be saved by enriching the blast air with oxygen if the blast air temperature is $500^{\circ} \mathrm{C}$ than if it is $800^{\circ} \mathrm{C}$. The simulations explain why operators of cupola furnaces have observed different effects of changes in operating conditions.

\section{Acknowledgement}

This work is part of the research programme of RocKWOOL ${ }^{\circledR}$ International A/S carried out in cooperation with CAPEC (Computer Aided Process Engineering Centre) and CHEC (Combustion and Harmful Emission Control) at the Department of Chemical Engineering, Technical University of Denmark. The project is funded by RocKWOOL ${ }^{\circledR}$ and Erhvervsfremmestyrelsen (Danish Ministry of Business and Industry), and the industral Ph.D. programme is adminestrated by the Academy of Technical Sciences.

\section{References}

J.E. Dennis and R.B. Schnabel. Numerical Methods for Unconstrained Optimisation an Nonlinear Equations. Prentice-Hall Inc., 1983.

R.H. Hafner. Cupola Handbook. American Foundrymen's Society, 5th ed. edition, 1984. 
R. Leth-Miller, A. Jensen, P. Glarborg, S. B. Jørgensen, L.M. Jensen, and P.B. Hansen. Experimental investigation and mathematical modelling of a mineral melting cupola furnace. Industrial and Engineering Chemistry Research (submitted), 2002a.

R. Leth-Miller, A.D. Jensen, P. Glarborg, S. B. Jørgensen, L.M. Jensen, and P.B. Hansen. Experimental investigation and modelling of heat capacity, heat of fusion and melting interval of rocks. Thermochemica Acta (submitted), 2002b.

R. Leth-Miller, J. Jensen, A.D. Jensen, P. Glarborg, S. B. Jørgensen, L.M. Jensen, and P.B. Hansen. Compartive study of coke reactivity towards $\mathrm{CO}_{2}$. Ironmaking and Steelmaking (submitted), 2002c.

Rice and Do. Applied Mathematical Modelling for Chemical Engineers. John Wiley and sons Inc., 1995.

J. Villadsen and M.L. Michelsen. Solution of Differential Equation Models by Polynomial Approximation. Prentice Hall, 1978.

N.N. Viswanathan, M.N. Srinivasanand, and A.K. Lahiri. Steady state threedimensional mathematical model for cupola. Ironmaking and Steelmaking, 24 (6):476 - 483, 1997. 